\title{
Investigation of Flow Energy Dissipation over Different Stepped Spillways
}

\author{
${ }^{1}$ G.A. Barani, ${ }^{2}$ M.B. Rahnama and ${ }^{2}$ N. Sohrabipoor \\ ${ }^{1}$ C.E. Department, Shahid Bahonar University, Kerman, Iran \\ ${ }^{2}$ Irrigation Department, Shahid Bahonar University, Kerman, Iran
}

\begin{abstract}
In this study, to investigate energy dissipation of flow overstepped spillways of different step shapes, a physical wooden model has been built in the Shahid Bahonar University's hydraulics lab. This model with $41.41^{\circ}$ slope has $84 \mathrm{~cm}$ height and 21 steps. Each step has $4 \mathrm{~cm}$ height, $4.5 \mathrm{~cm}$ width and $30 \mathrm{~cm}$ length. Experiments have been carried out for different types of step shapes (plain steps, end sill steps with thickness of 1,2,3 and $4 \mathrm{~cm}$ and steps with a bottom adverse slope of 15, 26, 36 and $45^{\circ}$ ). Overall, 131 experiments were done, the hydraulic parameters of flow over the model were measured and the energy dissipation of flow was calculated. Results show that the energy dissipation of flow on end sill and inclined stepped spillways are more than the plain one, it is increased by increasing the thickness of end sill or the adverse slope size. Comparison of flow energy dissipation over end sills stepped spillway and inclined type show that the inclined type has been dissipated more energy than the equivalent end sill type. Also for stepping spillway of different step shapes, flow energy dissipation decreases with increasing the flow rate. It is concluded that for a large stepped spillway with high flow rate the inclined type spillway is more effective than the other forms.
\end{abstract}

Key words: Stepped spillway, energy dissipation, end sill steps, inclined steps, physical model

\section{INTRODUCTION}

The spillway is a major part of a dam, which is built to release the flood flow. Design and contraction of spillways are very expensive and include a major part of the dams contraction cost. For large dams it is about $20 \%$ of total dams construction cost, and for small dams about $80 \%^{[1]}$. Depend on the hydraulic conditions of flow and the geologic characteristics of the dams site Spillways can be built with different types and shapes. Due to the high flow discharge over the spillways, their design and construction is very complicated and usually faced with difficulties such as cavitations and high flow kinetic energy. For example, the amount of energy which should be dissipated at the toe of the Tarbella dam's spillway is about 40000 MW which is about 20 times of the constructed power station capacity ${ }^{[2]}$. It becomes usual to protect the spillway surface from cavitations erosion by introducing air next to the spillway surface using aeration devices located on the spillway bottom and sometimes on the side walls ${ }^{[3]}$.

It is known that flow in a stepped channel could be in either a jet (nape) flow or skimming flow ${ }^{[4]}$. In a stepped spillway, jet flow would occur at relatively smaller discharges and skimming flow occurs at larger discharges. It also appears that for a wide range of slopes, the transition from the (lower) jet flow to the (higher) skimming flow occurs when $\mathrm{y}_{\mathrm{c}} / \mathrm{h}$ is approximately equal to 0.8 , where $\mathrm{y}_{\mathrm{c}}$ is the critical depth and $\mathrm{h}$ is the height of the steps ${ }^{[5]}$. Stepped spillways allow continuously dissipating a considerable amount of the flow kinetic energy, such that the downstream stilling basin, where the residual energy is dissipated by hydraulic jump, can be largely reduced in dimensions. Also, the cavitations risk along the spillway decreases significantly due to smaller flow velocities and the large air entertainment rate $^{[4]}$. Stepped spillways have regained popularity over the last two decades, thanks to financial benefits resulting mainly from the simple economic and the rapid construction procedure especially with the Roller Compacted Concrete (RCC) construction method ${ }^{[6]}$.

Experiments on a moderately sized stepped spillway indicate that the energy loss due to the steps depends primarily on the ratio of critical depth $\left(\mathrm{y}_{\mathrm{c}}\right)$ to the height of the step (h) as well as on the number of steps $(\mathrm{N})$. For small values of $\mathrm{y}_{\mathrm{c}} / \mathrm{h}$ near unity, or near the limit of skimming flow, the stepped surface is very effective in dissipating energy. For higher values of $\mathrm{y}_{\mathrm{c}} / \mathrm{h}$, the effect of $\mathrm{N}$ becomes appreciable, at a certain $\mathrm{y}_{\mathrm{c}} / \mathrm{h}$ the relative energy loss increases with $\mathrm{N}^{[7]}$. Based on the observation of velocity and air concentration profiles in the skimming flow on a large model of a stepped spillway for two slopes, a range of discharges and $\mathrm{y}_{\mathrm{c}} / \mathrm{h}$ of $0.7-4.4$, it was concluded that the relative energy loss in the stepped spillway was in the rang of $48-63 \%{ }^{[5]}$. Stepped spillways can be also designed as multipurpose systems, as examples, river training, water quality systems, and beautiful landscape of $\mathrm{dam}^{[8]}$. 


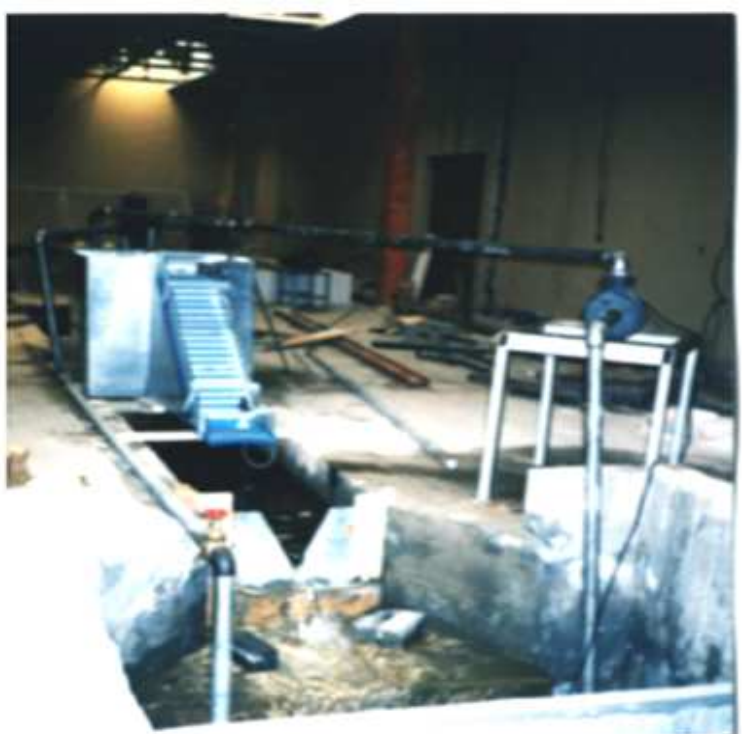

Fig. 1: Plan view of stepped spillway physical model

Experiments on two sets of physical models of steps spillways of slope upon 0.6 with the same crestshape, $30 \mathrm{~m}$ height and a range of step sizes $(0.25-2 \mathrm{~m}$ on the $1: 10$ scale and $0.5-2.0 \mathrm{~m}$ on the $1: 20$ scale models) showed that the residual specific energy is independent of these step sizes. But this energy at the toe of a $50 \mathrm{~m}$ high (or higher) stepped spillway, within the range of step heights tested, is less than $60 \%$ of the residual specific energy at the same level on a similar smooth spillway experiencing flows up to $20 \mathrm{~m}^{3} \mathrm{sec}-$ $\mathrm{m}^{-1[9]}$.

In the present study, the physical wooden model of Manksvill dam spillway with 1:25 scale has been built, Fig. 1. Three sets of experiments were carried out on this model, the first set of plain steps, the second on end sill steps and the last one on the steps with bottom adverse slope (hereafter for simplicity called inclined) steps. The hydraulic parameters of flow over the model were measured, the dissipated energy of flow was calculated, and the related equations were driven and introduced.

Physical model: A physical model of the Manksvill dam spillway has been built from wood. The toe elevation of this dam is $85.3 \mathrm{~m}$, crest elevation 106.325 $\mathrm{m}$, width of the spillway is $61 \mathrm{~m}$, the maximum flow per unit width of the spillway (q) is $6 \mathrm{~m}^{3} \mathrm{Sec}-\mathrm{m}^{-1}$, the maximum flow passing over the spillway $(\mathrm{Q})$ equal to $366 \mathrm{~m}^{3} \mathrm{sec}^{-1}$ and the hydraulic head above the spillway is $2.6 \mathrm{~m}$.

The minimum scale for physical models, which is recommended by USBR, is $1: 60^{[10]}$, so the scale of this physical model was selected 1:25.

This model was built from wood and painted such that its roughness coefficient becomes very low, in agreement with the concrete roughness coefficient.

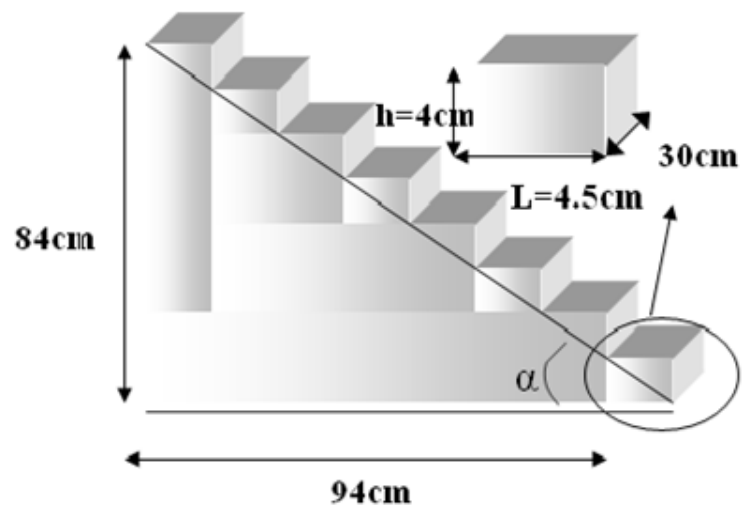

Fig. 2: Details of steps spillway physical model (stepped spillway plain view)

The minimum width of spillway recommended by USBR for two-dimensional models is $15 \mathrm{~cm}^{[11]}$, so for this model it was selected $30 \mathrm{~cm}$. The vertical height of the model (difference between the crest and toe elevations) is $0.84 \mathrm{~cm}$. The maximum flow passing over unite width of the model is $0.048 \mathrm{~m}^{3} \mathrm{sec}-\mathrm{m}^{-1}$, as a result, the maximum flow passing the model equals $0.0144 \mathrm{~m}^{3} \sec ^{-1}\left(14.4 \mathrm{~L} \mathrm{sec}^{-1}\right)$. The optimum slope and step height of the model obtained using the feasible direction method are $41.41^{\circ}$ and $4 \mathrm{~cm}$ respectively ${ }^{[12]}$. So, the total head above the model crest, model height and length are $4 \mathrm{~cm}, 84 \mathrm{~cm}$ and $95 \mathrm{~cm}$ respectively. The width of the steps based on the model slope is $4.5 \mathrm{~cm}$ (Fig. 2).

A $53^{\circ} \mathrm{V}$-notch weir, which installed on the canal downstream of the model, was used to measure the flow rate passing the stepped spillway, Fig. 3b. An existing concrete storage tank of $7.2 \mathrm{~m}^{3}$ capacity was used to supply water for the model. Two electro pumps each one with $5 \mathrm{~L} \mathrm{sec}^{-1}$ capacity was used to supply energy for transfer of water from the concrete storage tank through a 2 inches pipe to the $1 \mathrm{~m}^{3}(1 \times 1 \times 1 \mathrm{~m})$ storage reservoir tank located upstream of the model, Fig. $3 \mathrm{a}$. To reduce the turbulence of the flow, a $1 \times 1 \mathrm{~m}$ plate contains 25 holes $(5 \times 5$ holes each hole with $3 \mathrm{~cm}$ diameter), installed vertically inside the model reservoir tank at $25 \mathrm{~cm}$ distance from its beginning. The vertical and horizontal distances between two adjacent holes are $14 \mathrm{~cm}$ and from the plate edges is $14.5 \mathrm{~cm}$ for the outer holes, Fig. 3c. An eighty-two $\mathrm{cm}$ canal with $30 \mathrm{~cm}$ width and $15 \mathrm{~cm}$ height connects the reservoir tank to the step spillway, a series of metal network instated at the beginning of this canal to dissipate flow energy. At the toe of model, a $40 \mathrm{~cm}$ canal with $30 \mathrm{~cm}$ width and $15 \mathrm{~cm}$ height connects the stepped spillways to the concrete storage tank.

Five sets of wooden pieces (each set 21 pieces) with $30 \mathrm{~cm}$ length, $1.5 \mathrm{~cm}$ width and thicknesses of 1 , $1.5,2,3$ and $4 \mathrm{~cm}$ were put at the edge of the steps to convert them to the end sill types. 


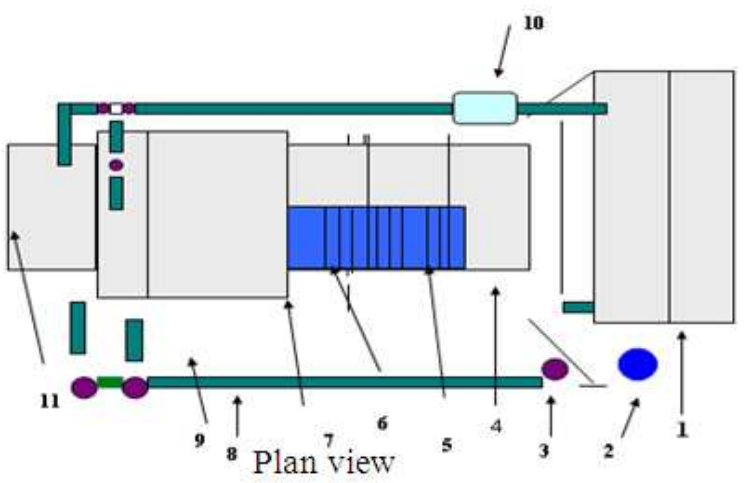

(a) 1-Storage tank, 2-Pump, 3-Valve, 4-Outlet canal, 5-stepped spillway model, 6-Inlet canal, 7-Stilling storage, 8-Pipes, 9-Hole-plate, 10-Extra pump, 11Canal

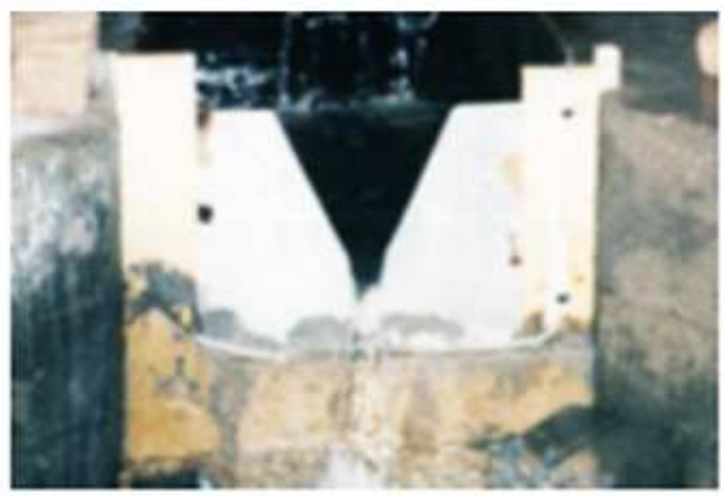

V-notch weir

(b)

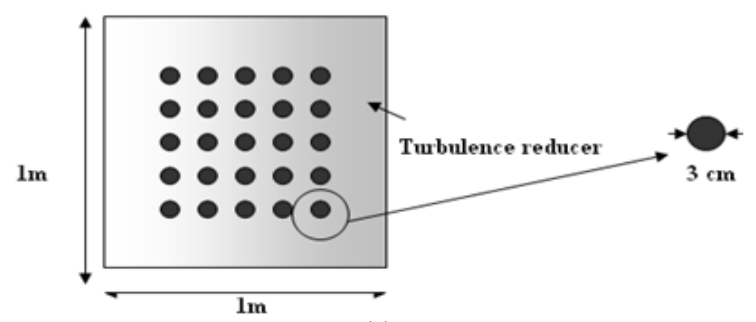

(c)

Fig. 3: Different parts of stepped spillway model (a), Vnotch weir (b), and turbulence-reducer plate of the reservoir tank (c)

Also, four sets of wooden triangular-shape pieces with $30 \mathrm{~cm}$ length and a range of thicknesses $(1,2,3$ and $4 \mathrm{~cm}$ ) were added at the bottom of plain steps such that to produce adverse bottom slope steps with 15, 26, 36 and $45^{\circ}$ (Fig. 4). A water gage with $0.05 \mathrm{~mm}$ accuracy was used to measure the depth of flow at the model upstream and downstream canals, and a piezometric tube installed at the downstream canal, above the v-notch weir, to determine depth of water $\left(\mathrm{H}_{\mathrm{w}}\right)$ and calculate flow rate.

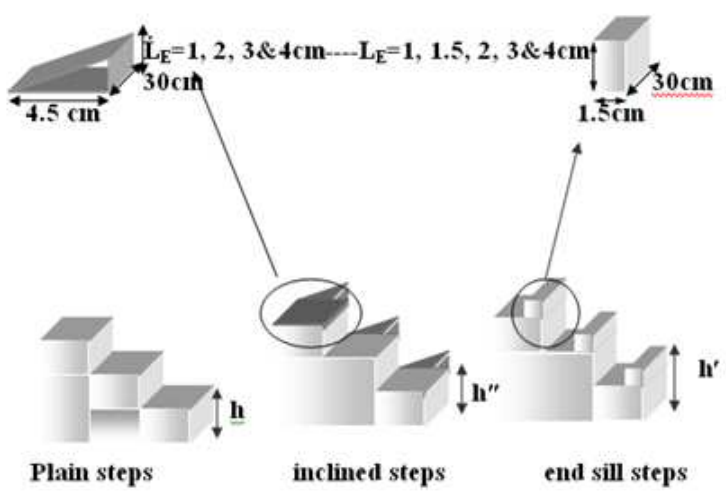

Fig. 4: Details of steps spillway physical model, plain steps, inclined steps, and end sill step

General equation: Energy dissipation on a stepped spillway is affected by several parameters such as the head of water above the spillway crest $(\mathrm{H})$, depth of flow over the steps (D), step height perpendicular to the model slope $\left(h_{1}\right)$, flow mean velocity $(\mathrm{V})$, density of water $(\rho)$, general slope of the model $(\operatorname{tg} \alpha)$, dynamic viscosity of flow $(\mu)$ and gravity acceleration $(\mathrm{g})$ or:

$F\left(E_{1}, E_{0}, E_{l}, H, D, h_{1}, V, \rho, \operatorname{tg} \alpha, \mu, g\right)=0$

Which $E_{1}$ and $E_{0}$ are flow kinetic energy at upstream and downstream of the stepped spillway respectively, and $\mathrm{E}_{l}$ is the flow energy dissipation $\left(\mathrm{E}_{l}=\mathrm{E}_{1}-\mathrm{E}_{0}\right)$. The percentage of dissipated energy using dimensional analysis and experimental data of steps spillways models was introduced ${ }^{[13]}$ as:

$\% \mathrm{E}_{\mathrm{L}}=104.33\left(\mathrm{H} / \mathrm{h}_{1}\right)^{-0.015} \mathrm{C}_{\mathrm{D}}{ }^{0.054}$

Where:

$\mathrm{C}_{\mathrm{D}}=3.285 \mathrm{R}_{\mathrm{e}}^{-0.013} \mathrm{~F}_{\mathrm{r}}^{-2.021}\left(\mathrm{D} / \mathrm{h}_{1}\right)^{0.015}(\operatorname{tg} \alpha)^{0.547}$

In which $R_{e}$ and $F_{r}$ represent Reynolds and Froude numbers respectively and $C_{D}$ is the form drag coefficient.

Experiments: To calibrate the V-notch weir located at the canal downstream of the model, overall 22 different flow rates $\left(0.8\right.$ to $\left.10 \mathrm{~L} \mathrm{sec}^{-1}\right)$ have been supplied to the model, for each flow rate the depth of water downstream of the model (a short distance before the V-notch weir) was measured. To determine the flow rate in each stage, change in volume of the storage reservoir tank and its related time was measured. A piezometric tube, which was installed on the canal upstream of the weir, has been used to measure the depth of water above the weir. Using the measured data and regression model, the weir equation obtained as:

$\mathrm{Q}=0.81 \mathrm{H}_{\mathrm{w}}^{2.5}$ 
To determine the flow kinetic energy upstream $\left(\mathrm{E}_{1}\right)$ and downstream (at the toe) of the model after the hydraulic jump $\left(\mathrm{E}_{2}\right)$, a water gage with $0.05 \mathrm{~mm}$ accuracy was used to measure the depth of the flow upstream $\left(\mathrm{y}_{1}\right)$ and downstream $\left(\mathrm{y}_{2}\right)$ of the model. Overall 131 experiments with different flow rates and step shapes (plain steps (24 experiments), end sills steps with five different thicknesses (53 experiments) and inclined steps with four different slopes (54 experiments) have been carried out. Depths of flow $y_{1}$ and $\mathrm{y}_{2}$ were measured, their related kinetic energy was calculated, and the percentage of dissipated energy $(\% \mathrm{E})$ was determined.

\section{RESULTS}

The dissipated energy of flow over the stepped spillway model with different step shapes, were plotted as a function of flow rate in Fig. 5 and 6. As shown on Fig. 5, the dissipated energy of flow over the model with end sill steps is more than the plain form and it increases by increasing the end sill sizes. Also, the same behaviors can be seen in Fig. 6 for flow over the model with inclined steps. Dissipated energy increases by increasing the degrees of slopes. Both, Fig. 5 and 6 show that the flow energy dissipation decreases with increasing the flow rate over the model.

Comparison of flow energy dissipation of a model with a specific size of end sill steps and equivalent size of inclined steps show higher dissipated energy for inclined type steps (Fig. 7 and 8 as two examples).

To determine equivalent equations of (2) and (3) for the present model with end sill steps, let $h_{2}=h^{\prime} \cos$ $(\alpha), h^{\prime}=h+L_{E}$ in which $L_{E}$ represents the thickness of end sill and $h$ step height of the model Fig. (4).

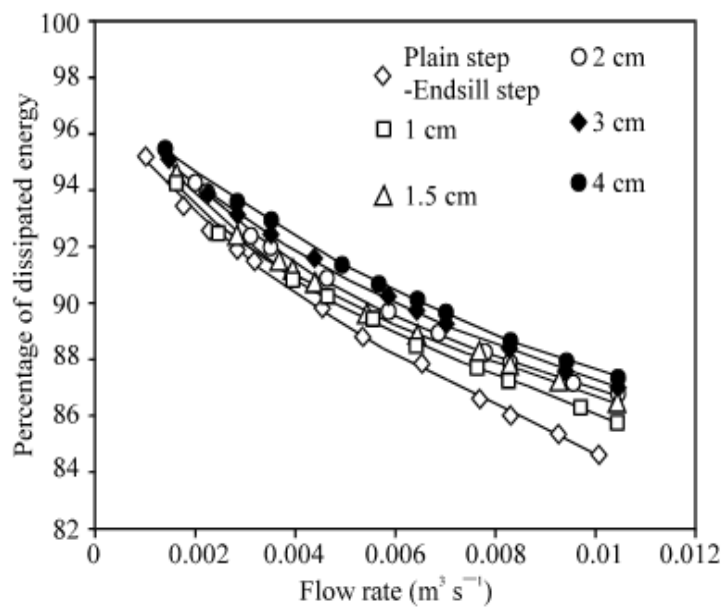

Fig. 5: Energy dissipation of flow over end sills stepped spillway for different end sill size

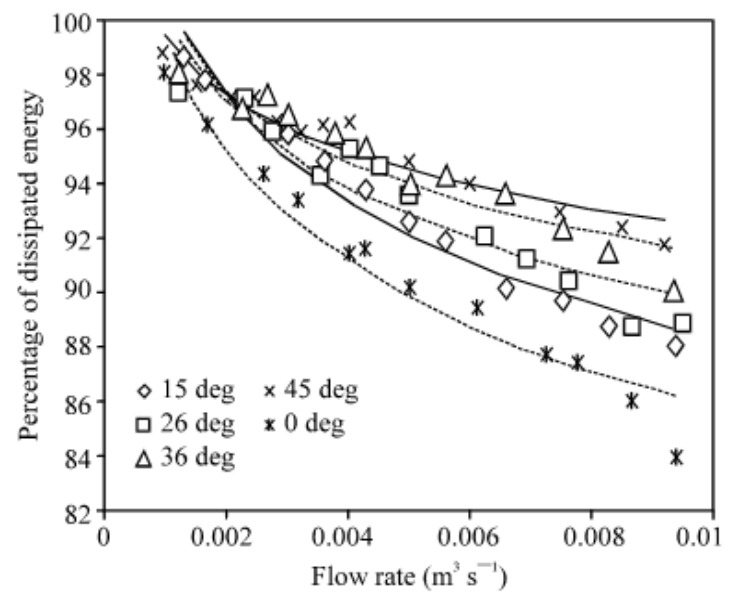

Fig. 6: Energy dissipation of flow over an inclined stepped spillway for different slopes

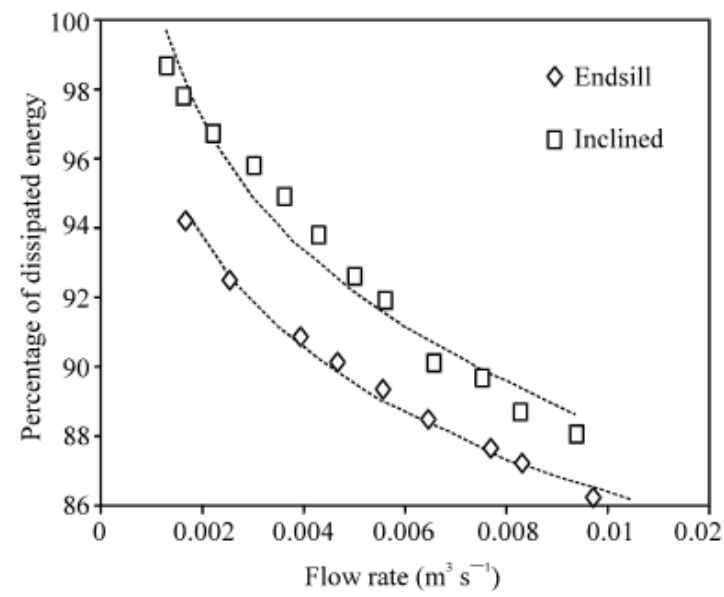

Fig. 7: Energy dissipation of flow over end sills stepped spillway (1-cm thick) and inclined stepped spillway $\left(15^{\circ}\right)$

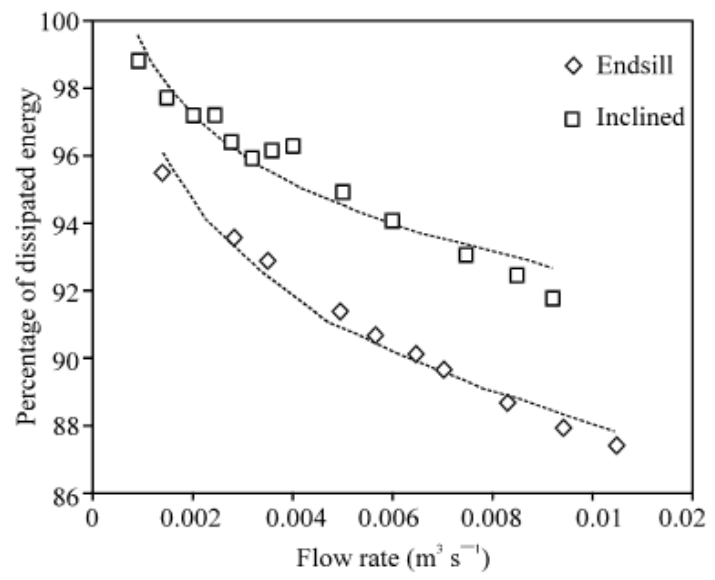

Fig. 8: Energy dissipation of flow over end sills stepped spillway (4-cm thick) and inclined stepped spillway $\left(45^{\circ}\right)$ 
Using dimensional analysis, the flow measured data over the end sill stepped spillway model and regression method the best equation for the drag coefficient $\left(\mathrm{C}_{\mathrm{D} 1}\right)$ had been obtained as:

$\mathrm{C}_{\mathrm{Dl}}=2.781671 \mathrm{Fr}^{-2.003140} \mathrm{R}_{\mathrm{e}}{ }^{0.0000778}\left(\mathrm{D} / \mathrm{h}_{2}\right)^{-0.010175} \operatorname{tg}(\alpha)^{0.633887,}$

$\mathrm{R}^{2}=0.9999$

Finally, the energy dissipation equation of flow over end sills stepped spillway had been obtained as:

$\% \mathrm{E}_{l 1}=89.0849 \mathrm{C}_{\mathrm{D} 1}{ }^{0.004975}\left(\mathrm{H} / \mathrm{h}_{2}\right)^{-0.081883}, \mathrm{R}^{2}=0.984115$

Also, by the same procedure the equations of the form drag coefficient $\left(\mathrm{C}_{\mathrm{D} 2}\right)$ and energy dissipation of flow over an inclined stepped spillway $\left(\% \mathrm{E}_{l 2}\right)$ were obtained as:

$$
\begin{aligned}
& \mathrm{C}_{\mathrm{D} 2}= 42.50917 \mathrm{Fr}^{-0.186512} \mathrm{R}_{\mathrm{e}}^{-0.334809}\left(\mathrm{D} / \mathrm{h}_{3}\right)^{0.377224} \operatorname{tg}(\alpha)^{1.403735}, \\
& \mathrm{R} 2=0.854388 \\
& \% \mathrm{E}_{/ 2}=89.15001 \mathrm{C}_{\mathrm{D} 2}{ }^{0.005937}\left(\mathrm{H} / \mathrm{h}_{3}\right)^{-0.071644}, \mathrm{R}^{2}=0.877663
\end{aligned}
$$

In which $h_{3}=h^{\prime \prime}$. Cos $(\alpha), h^{\prime \prime}=h+L_{E}$, and $L_{E}$ is the size of the triangular shape pieces for converting the plain steps to inclined ones, Fig. 4.

\section{CONCLUSION}

The results of 131 experiments, which were carried out on the stepped spillway physical model with different step shapes (plain, end sill and inclined) show that, the energy dissipation of flow over the stepped spillway model with end sill and inclined steps are more than plain form. In equivalent conditions, the inclined steps spillways dissipate more energy than the end sill one. It is concluded that for small dams with low flow rate over the spillway, stepped shape spillway can be dissipated most of the flow kinetic energy, and the need for construction of stilling basin at the toe of spillway becomes negligible. For larger dams with higher flow rate over the spillway, the inclined type stepped spillway can be more effective than the end sill type. Introducing equations (6) and (8) confirm the capability of calculating the dissipated energy of flow over the end sill and inclined types of stepped spillways, respectively.

\section{REFERENCES}

1. Yousefian, H., 1996. Hydraulic design of the Labyrinth spillways based on the physical model. M.Sc. Thesis, Isfahan University of Technology, Iran.

2. Novak, P., A.I.B. Maffat, R. Narayanan, 1990. Hydraulic structures. Published by the academic division of uniwin Ltd., pp: 546.

3. Chanson, H., 1997. Air bubble entertainment in free-surface turbulent shears flows. Academic Press, London, UK, pp: 401.

4. Rajaratnam, N., 1990. Skimming flow in stepped spillway. J. Hydraulic Eng., ASCE, 116: 587-691.

5. Chamani, M.R. and N. Rajaratnam, 1999. Characteristic of skimming flow over stepped spillways. J. Hydraulic Eng., 125: 361-367.

6. Sorenson, R.M., 1985. Stepped spillway hydraulic model investigations. J. Hydraulic Div. ASCE, Ш: 1461-1472.

7. Christodoulou, C., 1993. Energy dissipation on stepped spillways. J. Hydraulic Eng., 119: 644-650.

8. Chanson, H., 2000b. Forum article. Hydraulics of stepped spillway: Current status. J. Hydraulic Eng. 126: 636-637.

9. Pegram, G.G.S., A.K. Officer and S.R. Mottram, 1999. Hydraulics of skimming flow on modeled stepped spillways. J. Hydraulic Eng., 125: 500-510.

10. Sharp, J.J., 1981. Hydraulic model. Butter woryh and co., London, UK.

11. Spiegel, M.R., 1961. Statistics schemes outline series. McGraw Hill Book Company.

12. Bagheri, H., 2002. Optimization and physical modeling of steps spillway. M.Sc Thesis C.E. Dept. Shahid Bahonar University, Kerman, Iran.

13. Yazdani, A., 1998. Investigation of slope effect on flow energy dissipation over stepped spillway. Intl. J. Sci. Eng. (in Persian), 9: 1-13. 